MEI

II, vol. 3

$n^{0} 4$

\title{
El Archivo de la Facultad de Educación de León al servicio de la retroalimentación educativa
}

\author{
María del Carmen Rodríguez López \\ Departamento de patrimonio artístico y documental (Universidad de León)
}

Recibido el 14-06-2011 Aceptado en 22-09-2011

\section{Resumen}

El objetivo principal con que se acometió este trabajo no fue otro que hacer un primer acercamiento a las posibles aplicaciones didácticas del llamado «patrimonio virtual» para la enseñanza de materias histórico-educativas. Los nuevos planes de estudio adaptados al Espacio Europeo de Educación Superior inciden, de manera insistente, en una nueva planificación metodológica orientada a una menor presencialidad y a una mayor valoración del trabajo del estudiante. Puede ser este el momento en el que plantear el empleo de los bienes patrimoniales en el proceso de enseñanza-aprendizaje, mediante una primera aproximación a los beneficios que puede proporcionar un fondo como es el de la Facultad de Educación, tan dilatado en el tiempo, para la formación de los alumnos actuales. De entre todo el fondo sólo se trata del que incumbe a la «Escuela Normal Seminario de Maestros» de León, que empieza su actividad el 1 de septiembre de 1844 hasta que deviene en la actual Facultad de Educación en el curso académico 1976-1977. La metodología empleada parte de un Proyecto de Investigación en curso, que acomete la organización y descripción del fondo de la Facultad de Educación. Se han aplicado las técnicas archivísticas apoyadas en el principio de procedencia y el respeto al orden originario (no podría ser de otra manera) como en cualquier intervención archivística.

\section{Palabras clave}

Facultad de Educación, Escuela Normal de Maestros, León, Archivo, Organización de Fondos, Difusión de Fondos, Retroalimentación Educativa.

The Archive of the Faculty of Education León educational service feedback

Abstract

The main objective of this work was undertaken it was none other than make a first approach to the potential educational applications of so-called "virtual heritage" for the teaching of historical and educational materials. The new curricula adapted to the European Higher Education impact, so insistent, fall upon a new planning methodology aimed at lower and higher presence assessment of student work. Can this be the moment to raise the use of the assets in the teaching-learning process, through a first approximation to the benefits it can provide a background as that of the Faculty of Education, such a long time, for the training of current students. Among the entire holding is the only incumbent on the "Normal School Teachers Seminar" de Leon, who began working on September 1st, 1844 until the current becomes College of Education in the academic year 1976-1977.

The methodology part of an ongoing research project, which undertakes the organization and description of the collection of the Faculty of Education. Have applied the techniques supported by the archival principle of provenance and respect for original order (it could not be otherwise) and any archival intervention.

\section{Keywords}

Education Faculty, Normal School of Teachers, León, Archive, Holding organization, Holding dissemination, Educational feedback. 


\section{Introducción}

Periódicamente determinados términos se erigen en "estrellas mediáticas". De su condición de estrella no dimana que vayan a ser empleados esos términos con corrección, ni siquiera que estén conformes al español correcto. En el momento actual en el campo de las humanidades lo son: "calidad", "puesta en valor", "visibilización" o "memoria histórica", entre otras.

Según Javier Rodríguez González (2003) sólo el Diccionario de sociología recoge el uso colectivo, social y cultural del concepto de "memoria" en el momento en que aborda en dicha entrada la obra de Maurice Halbwachs (Ramos, 1988). Esta memoria histórica era la "memoria prestada" de acontecimientos del pasado que no se han experimentado personalmente. Rodríguez González define memoria histórica como el conjunto de aquellos acontecimientos del pasado retenidos (implicando selección) y mayoritariamente compartidos por los miembros de un país, o de otras unidades de convivencia casi siempre menores, cuyos miembros gocen de un sentimiento de identidad común. Cuando esta aparece unida a un acontecimiento cuya comprensión excede a los límites de la experiencia individual, acaba siendo enriquecida con aportaciones de diversas fuentes, con lo que se añade la dimensión colectiva o social al recuerdo en cuestión.

Conocer el pasado y rememorarlo son operaciones diferentes. Saber es cuestión de estudio, de documentación y de conocimiento. Saber es conocer algo o tener noticia o conocimiento de ello. Estar informado de la existencia, paradero o estado de algo o de alguien (RAE, 2001). Recordar es cuestión de voluntad, pero es evidente que nadie puede recordar aquello que no forma parte de su experiencia personal. Conocer el pasado no es pues función de la memoria. La historia es la que se esfuerza por conocer el pasado acudiendo a fuentes objetivas y aplicando los instrumentos propios de la crítica.

En el archivo, desde luego, no se hace memoria histórica. El archivo recoge la documentación producida o recibida por su sujeto productor, persona física o jurídica, en el ejercicio de su actividad. Cada actividad desarrollada queda plasmada en la documentación que de ella da fe. $\mathrm{El}$ archivo es la "caja negra" registro indeleble de cuanto ha sucedido y también -y no menos importante- de lo que nunca se llevó a cabo.

La difusión es una de las principales actividades de todo archivo. No se deben atesorar los fondos con un concepto patrimonialista, sino que hay que ponerlos a disposición de la entidad que los genera y del público, porque, aunque al ser un archivo de una institución docente tiene una función de magisterio innegable y una especificidad concreta, además de ser Patrimonio cultural de la sociedad española y castellano-leonesa, en general, y de la sociedad leonesa, en particular.

\section{La historia de la Escuela}

De «Escuela Normal Seminario de Maestros» de León se empieza a hablar el 31 de agosto de 1834 en la Gaceta, haciendo mención para la creación de una Escuela 
Normal de Maestros. Tendría que esperar el proyecto otros diez años en los que se diseñó el sistema de selección de candidatos a alumnado y a profesorado, la designación de patronos (Diputación Provincial y Ayuntamiento de León) y los exámenes para ocupar la dirección del centro. Como tal se crea por Real Decreto de 4 de octubre de 1843, siendo de carácter elemental y dependiente del distrito universitario de Oviedo. Comienza su actividad el 1 de septiembre de 1844, en las instalaciones del edificio del viejo convento de los Escolapios. El alumnado se formó con un becado por partido judicial, siendo estos partidos: León, Astorga, La Bañeza, Murias, Riaño, Sahagún, Valencia de Don Juan, La Vecilla, Ponferrada y Villafranca.

La plantilla inicial se compuso de dos maestros, un eclesiástico y un porteroconserje que también ejerce de secretario. En el año 1846 se examinaron ya once maestros. Por Real Orden de 1 de diciembre de 1860, la Normal leonesa adquiere el rango de superior. En el año 1896 se produjo un intento de suprimir la Escuela, aunque la Diputación de León asumió los gastos. Un año después, por Real Decreto de 2 de noviembre de 1897, se crea la «Escuela Normal de Maestras», ubicándose en el número cinco de la calle de Bayón, existiendo así dos edificios.

En el año 1924 la Normal de Maestros se muda a la calle del Cid, y la de Maestras estrena el inmueble del Grupo Escolar «Ponce de León», en la calle Serranos. Con el impulso dado al magisterio en la II República, en 1935 entra en funcionamiento el nuevo edificio de la calle Álvaro López Núñez. A partir de 1936 se vuelven a separar los alumnos de las alumnas. La designación de la Escuela de Magisterio de León como Centro Asociado de la UNESCO en el curso 1958-1959 da paso a una mayor tolerancia: se reunifican de nuevo las Escuelas, se funda el Instituto de Ciencias de la Educación (1969), y la Ley General de Educación de 1970 incorpora las Escuelas al estatus universitario.

La actual Facultad de Educación ${ }^{1}$ se crea en el curso académico 1976-1977. La Orden Ministerial de 1977 modifica las denominaciones a nivel nacional: los maestros pasan a ser profesores de EGB y las Escuelas Normales se transforman en Escuelas Universitarias de Formación del Profesorado de EGB. Ha pasado, como todos los otros centros españoles, por múltiples Planes de Estudios y Reformas Educativas (LRU, LODE, LOGSE, LOU) y la aprobación en 1995 del título de Licenciado en Psicopedagogía, transforman definitivamente las originarias Escuelas Normales en lo que hoy es la Facultad de Educación, definitivamente instalada en un nuevo edificio en la ampliación del campus de Vegazana (tras haber pasado por otro anterior en el propio Campus -que en menos de una década se quedó pequeño). Durante el curso (2010/2011) se han comenzado a impartir las nuevas enseñanzas que trae consigo el Espacio Europeo de Educación Superior: los títulos de Grado en Educación Infantil y Educación Primaria, así como los másteres².

\section{El proyecto de descripción del archivo}

En el año pasado de 2010 la Consejería de Educación de la Junta de Castilla y León aprobó subvencionar un proyecto de investigación titulado: Catalogación del fondo del archivo de la "Escuela de Magisterio" de León (1843-1977): Puesta en valor del 
fondo documental más antiguo de la ULE. El grupo de investigación está formado por María del Carmen Rodríguez López como investigadora principal del equipo formado por Ángela Diez Diez, Josefa Gallego Lorenzo, María Antonia Morán Suárez y Lourdes Santos de Paz. Todas ellas profesoras de la Universidad de León y vinculadas al grupo de investigación ANAQUEL: Sistemas de Información, Documentación y Archivo?

En un primer momento se ha trabajado con el fondo hasta el plan de estudios de 1967. Así lo aconseja el derecho de acceso y la protección de datos ${ }^{4}$.

Se desconoce cuándo se formó realmente el Archivo de la actual Facultad de Educación, pero a través de su propia documentación podemos aportar las fechas extremas de la documentación custodiada que engloban desde 1844 hasta hoy en día. Esta primera fecha corresponde a la serie documental de expedientes de alumnos, porque hay que precisar que la serie documental de actas de exámenes (la otra gran serie documental señera, de esta y de cualquier institución) tiene como libro más antiguo el del curso de 1868-1869.

El volumen documental tratado atendiendo a la forma de instalación, libro o caja (siempre ateniéndonos a la fecha final propuesta que se refiere al plan de 1967), arroja estas cifras:

\section{LIBROS}

Libros de actas de exámenes-147

Libros de registro de Títulos-6

Libros de matrícula -1

Libros de registro de entrada y salida de documentos- 1

Libros de calificación escolar -11 (10 libros de mujeres y 1 de varón huérfano militar. No deberían estar en este fondo)

El resto de los libros propios de un centro de estas características no se encuentran en este fondo.

\section{CAJAS Y LEGAJOS}

Un total de 775 cajas de expedientes de alumnos más otras 47 que contienen solicitudes. Los números de la serie documental de expedientes de alumnos son:

Plan antiguo:

Masculino: 189 cajas $=3.572$ expedientes

Femenino: 73 cajas $=1.668$ expedientes de alumnos

Plan moderno:

Masculino: 125 cajas $=2.483$ expedientes de alumnos

Femenino: $109=1.841$ expedientes de alumnas

Bachiller 1914:

Masculino y Femenino: 33 cajas $=1.926$ expedientes (mucho menos voluminosos)

Plan 1945:

40 cajas $=790$ expedientes 
Plan 1950:

Masculino: 73 cajas $=1790$ expedientes

Femenino:91 cajas $=2750$ expedientes

Plan 1967:

42 cajas $=1455$ expedientes

\section{El archivo y la retroalimentación educativa}

El patrimonio documental de la Facultad de Educación es una fuente de información insustituible que de poco serviría si no se tuviese en cuenta su preservación, conservación y difusión. El objetivo final de todo archivo es disponer de la documentación organizada, con información recuperable para su uso, tanto para la Universidad (administración productora) como para el usuario externo (legítimo interesado, investigador o ciudadano que ejerce su derecho a la información -siempre que se garanticen los derechos de protección de datos). En este objetivo final se vertebra lo que se ha venido a denominar retroalimentación o feedback como proceso en el que se comparten observaciones, preocupaciones y sugerencias con la intención de recabar información que permita un mejor funcionamiento, en este caso de la institución universitaria. Inicialmente estos pueden ser los aportes del archivo de la Facultad de Educación:

- Para la Comunidad Educativa en General: Recuperar la memoria de la Facultad es recuperar, también, la de las personas que trabajaron en esta institución, la de quienes innovaron y contribuyeron a su evolución, la de quienes hicieron de ella expresión de su ideología y, en fin, la de quienes fueron capaces de transmitir a sus discentes los valores de la cultura y de la ciencia, de la participación, de la responsabilidad y del trabajo. Aquilatando un poco más, el Patrimonio Educativo posibilita una iniciativa de estudios e investigaciones sobre instituciones docentes, desde estudios de tipologías de edificios docentes, por su interés histórico o artístico, organigramas corporativos y organizativos, sistemas de becas y política social, hasta investigaciones sobre documentos, textos y materiales empleados en la práctica educativa, pasando por exposiciones temporales y profundos trabajos sobre la evolución del pensamiento.

- Para la sociedad en general y la sociedad leonesa en particular. El patrimonio cultural es el conjunto de bienes culturales que la historia ha legado a una sociedad o a una colectividad y a los que ésta, en el presente, otorga valor histórico, científico o testimonial. Dentro de ese llamado patrimonio cultural, se incluyen testimonios tangibles como objetos, materiales, conjuntos arquitectónicos. La sociedad leonesa, por su parte, resultó notablemente enriquecida con este centro. Numerosos maestros y maestras (permítase este distingo por cuanto los centros fueron independientes largo tiempo) encontraron su futuro profesional desde la creación del centro.

- Para avanzar hacia la constitución del Patrimonio Virtual y la protección del mismo: Las tecnologías de la información y la comunicación y la aparición de nuevos formatos y soportes para generar y guardar documentos electrónicos, hace que a las dos categorías de bienes integrantes del Patrimonio Documental, 
los que se encuentran en espacio abierto, o cerrados, debamos añadir aquellos que se encuentran en formato electrónico, y más concretamente, los que se encuentran en el ciberespacio, es decir, en Internet. Se trata del patrimonio digital, que, a diferencia de las dos tipologías anteriores, no es real y tangible, sino virtual. En consecuencia, todos los bienes patrimoniales «tangibles»o «reales» pueden convertirse en virtuales, de manera que pueden hacerse accesibles a través de un soporte electrónico como Internet, un CD-ROM, etc. Digitalizar el fondo y las imágenes de los materiales educativos es un paso más al servicio de sus usuarios que la Facultad habrá de plantearse.

- Para los discentes: Las materias histórico-educativas de los nuevos planes de estudio adaptados al Espacio Europeo de Educación Superior, que, entre otras cosas, requieren una nueva planificación metodológica orientada a una menor presencialidad y a una mayor valoración del trabajo del estudiante, disponen de un recurso nato bien poco o nada empleado, a saber: el empleo de los bienes patrimoniales en el proceso de enseñanza-aprendizaje. Así se percibe la siguiente aplicación:

- Para las Ciencias de la Administración existe la posibilidad de estudiar los procesos administrativos a lo largo de siglo y medio; estudio del trámite administrativo y de la transparencia administrativa.

- En el campo de las Ciencias de la Educación: Historia de la Educación; estudio de planes docentes y cuadros de asignaturas; permanencia.

- Historia del Magisterio leonés. De la lectura de toda la bibliografía sobre la Escuela Normal Leonesa se desprende que las fuentes manejadas, casi siempre, son indirectas. Se citan boletines de la provincia, gacetas, anuarios, etc. En esos datos, hay desencuentros en asuntos como el número de alumnos de los primeros cursos. Las actas de exámenes documentan con exactitud tales datos. También estudios de tipologías de edificios escolares; documentos, textos y materiales empleados en la práctica educativa, etc.

- Historia: Biografías de personajes leoneses ilustres, que también estuvieron vinculados al magisterio (Belinchón, Argüello, etc.); depuración del Magisterio Leonés durante la Guerra Civil, etc.

Como profesora de las asignaturas de Archivística, mis alumnos se enriquecen con visitas a los fondos de la ULE que, sus respectivos decanos, permiten generosamente. Aprenden sobre instalaciones, su importancia en la preservación documental, cuál es el mejor sistema de organización y ordenación de cada serie documental, qué datos quieren tener disponibles para recuperar, cómo diseñar su propia base de datos que relacione datos, jerarquías organizadoras y plazos de conservación y acceso. Comprenden también qué datos son más vulnerables y deben tener acceso restringido, etc.

\section{Aprovechamiento de las dos series documentales más voluminosas}

Dos series documentales, de entre las generadas por la historia de un centro educativo, son las más indicadas para dar idea de la riqueza del Patrimonio de la 
Facultad de Educación, la información que contienen y una breve sugerencia de los estudios que sobre ellas se podrían llevar a cabo: actas de exámenes y expedientes de alumnos.

Ya que no existe ninguna normativa específica de condiciones de utilización de este Archivo, serán de aplicación las mismas que para cualquier otro Archivo de una Administración Pública, con las correspondientes restricciones que figuran en las normas de aplicación general, esto es, la Constitución española de 1978 (art. 105), la LRJAPyPAC (Ley de Régimen Jurídico de las Administraciones Públicas y Procedimiento Administrativo Común, 30/1992, art. 37) y la ley que la modifica (Ley 4/1999), el Código Penal (Ley Orgánica 10/1995, de 23 de noviembre, del Código Penal, Cap. IV), la ley del Patrimonio Histórico Español (Ley 16/1985, art. 57), la LORTAD (Ley Orgánica 5/1992 de 29 de octubre de Regulación del Tratamiento Automatizado de los datos de Carácter Personal), y la Ley de protección de datos (Ley Orgánica 15/1999, de 13 de diciembre de Protección de Datos de Carácter Personal).

Básicamente, el derecho de acceso será ejercido por los particulares de forma que no se vea afectada la eficacia del funcionamiento de los servicios públicos, mediante petición de los documentos que se desee consultar. Cuando los solicitantes sean investigadores que acrediten un interés histórico, científico o cultural relevante, se podrá autorizar el acceso directo de aquéllos a la consulta de los expedientes, siempre que quede garantizada debidamente la intimidad de las personas.

\section{Expedientes de alumnos}

Para este estudio nos remontamos a los expedientes de alumnos del plan antiguo, con exclusividad. El diseño de la carpetilla contenedora de cada expediente es adecuado, aunque no hay membrete si está la denominación del centro: Escuela Normal Superior de Maestros de León. Después el título del documento: "Expediente de...”; a continuación el "índice de los documentos que contiene", que en general son:

1. Hoja de estudios

2. Solicitud pidiendo el ingreso

3. Fe de bautismo

4. Certificación de buena conducta

5. Certificado de no padecer enfermedad contagiosa

6. Autorización del para seguir la carrera

7. Papeleta pidiendo examen

8. Certificación de su resultado

9. Papeleta pidiendo examen

10. Certificación de su resultado

11.Solicitud pidiendo examen de reválida y certificación de su resultado

12.Ejercicios escritos del mismo

13.

14.Etc.

El documento de mayor concentración informativa es la "Hoja de Estudios" de este 
documento procede buena parte de la información necesaria (pero no toda como la fecha de nacimiento y la de título). En primer lugar proporciona el nombre completo de la institución; nombre que coincide con el otorgado en las Actas y que sirve para elegir la denominación de autoridad para la institución: "Escuela Normal Superior de Maestros de León”, “Escuela Normal de Maestras de León”, etc. A continuación los datos de identificación del alumno: nombre y apellidos, lugar de nacimiento y edad. Las fechas de matrícula, modalidad (oficial o libre) por cada curso académico, a las que sigue la información sobre el currículo del alumno, a saber: nombre de las asignaturas, asistencia, conducta y aplicación, calificación en los exámenes ordinarios y extraordinarios. Por último las fechas de los exámenes de reválida, con la calificación (o censura) del ejercicio escrito, oral y práctico.

Estas calificaciones, que ocupan la parte final del documento están previstas tanto para el título de Maestro de Primera Enseñanza Elemental y para obtener el título de Maestro de Primera Enseñanza Superior.

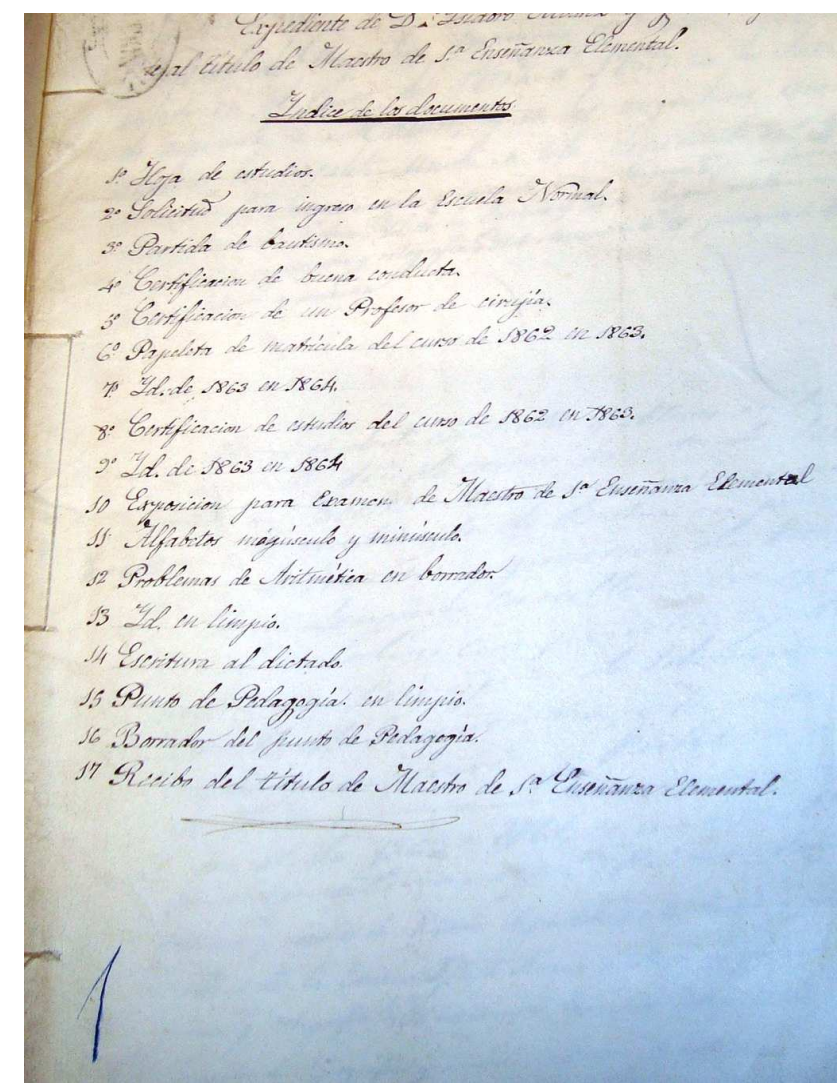

\footnotetext{
Ilustración 1. Relación de contenido de un expediente. Los datos nominales han sido omitidos a propósito. Fotografía hecha por Carmen Rodríguez López
}

Entre estos expedientes del plan antiguo se encuentran salpicados los expedientes de maestras, no disponen de la misma carpetilla que los demás y la documentación que contienen es diferente: 
1. Instancia solicitando examen de maestra

2. Partida de bautismo

3. Certificación de buena conducta

4. Lista de labores

5. Alfabetos

6. Ejercicios de aritmética

7. Id. en limpio

8. Escritura al dictado

9. Ejercicios de aritmética en borrador para la enseñanza superior

10.Los mismos en limpio

11.Punto de pedagogía en borrador

12.Id. en limpio

13. Certificación de buena conducta

14. Recibo del título

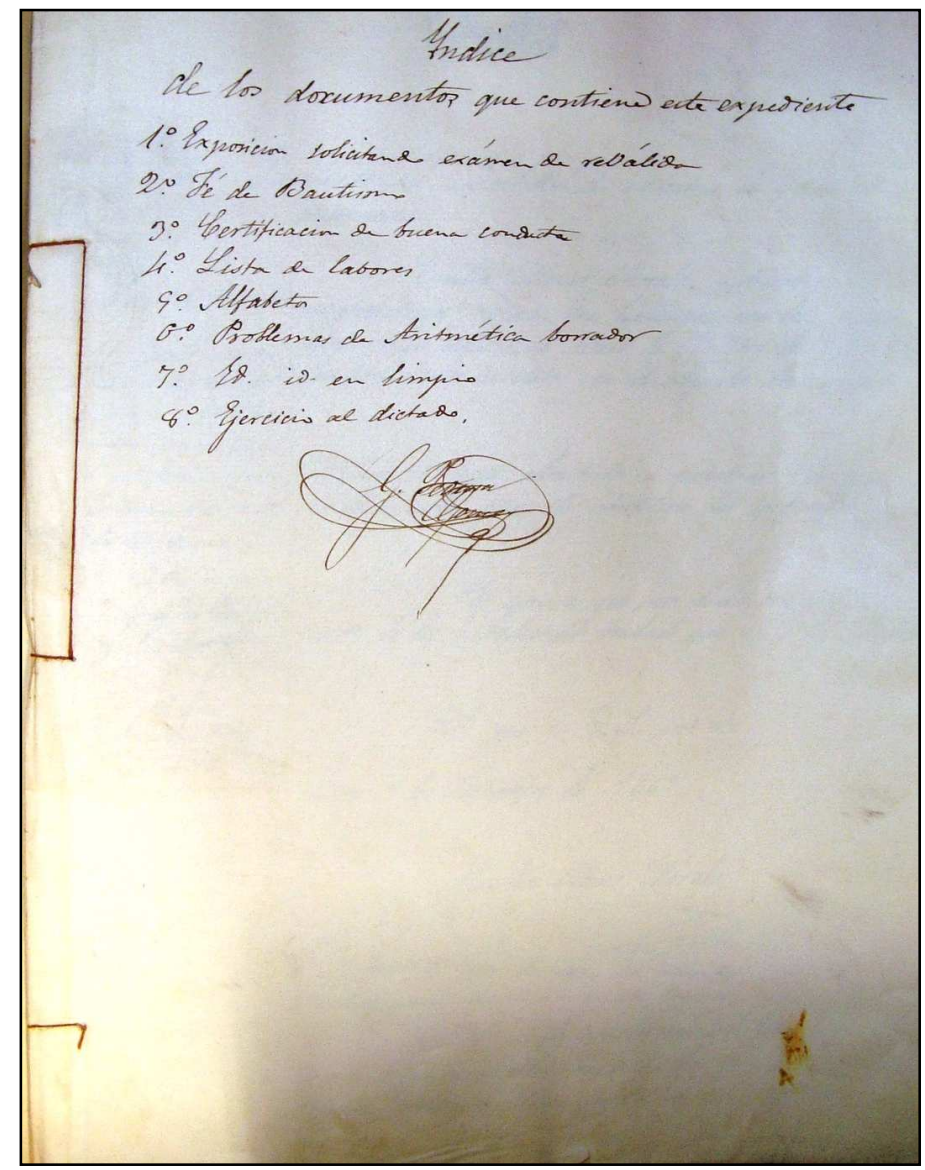

Ilustración 2. Relación de contenido de un expediente de una alumna. Los datos nominales han sido omitidos a propósito. Fotografía hecha por Carmen Rodríguez López

Las fechas extremas de inicio y finalización del expediente académico, correspondientes con la fecha de matrícula y la fecha de examen final para la obtención del título permitirán su explotación para conocer datos de permanencia. 
Otros estudios que podrían abordarse serían la procedencia de los alumnos y la cuantificación de estos datos entre sexos. Los estudios más completos podrían hacerse sobre los usos administrativos como el procedimiento de matrícula; la práctica habitual era realizar la matrícula en mayo o septiembre para la matrícula no oficial, es decir que sólo se presentaban a los exámenes de las convocatorias ordinarias y extraordinarias; diferentes usos administrativos entre los centros de maestros y maestras; cuadros de asignaturas; o prácticas ya derogadas como la certificación de buena conducta. El alcalde (constitucional, en este momento) es el encargado de hacer esta certificación, formulada generalmente en los siguientes términos: "ha observado una conducta irreprensible tanto en lo moral como en lo eclesiástico" y esta última aseveración se corrobora con el visto bueno del párroco ${ }^{5}$.

\section{Actas de exámenes}

Esta serie es de las más voluminosas junto con los expedientes de alumnos. Están encuadernadas en formato de libro de archivo, cubriendo un periodo de tiempo que va desde el curso de 1868-1869 hasta hoy en día. Sin duda la continuidad la convierte en una serie documental de gran valor para el archivo, para la Facultad de Educación, para los ex alumnos, para la sociedad leonesa en particular y para la sociedad española en general. Así se dispone de una fuente para documentar el número exacto de alumnos de las promociones (que en diferentes estudios sobre el centro son divergentes), los profesores responsables de las asignaturas, cargos del centro, o, como en la serie de expedientes de alumnos, los diferentes usos administrativos. En este sentido se proponen en las líneas sucesivas, sin pretensiones de exhaustividad, algunos de estos usos. Se trata de apuntes que podrían considerarse un catálogo de "la fecha en que por primera vez...”.

La primera fecha de que se dispone en el apartado de validación es de primero de junio de 1869. Evidentemente corresponde al curso académico 68-69 pero contiene los exámenes propiamente dichos de fechas anteriores. Este primer libro contiene las actas de notas de exámenes ordinarios, las actas de exámenes de fin de curso: enseñanza elemental y las actas de exámenes de fin de curso: enseñanza superior, datadas también en primero de junio. Firman las actas (de los siete primeros alumnos) Jacinto Arguello, director, Anastasio Prieto y Ángel Cid Conde, en $1^{\circ}$ de junio de 1869.

En algunas ocasiones firma Juan López, a falta de Ángel Cid. Las actas de 18691870 ya presentan una estructura diferente y parecen normalizadas, corresponden a los tres cursos y a los tres trimestres ordinarios, disponiendo una columna para los extraordinarios. En el curso de 1871-1872 ya aparece la convocatoria extraordinaria de febrero. Otro elemento novedoso es el jurado para las asignaturas, compuesto, según las firmas, por el profesor oficial de una asignatura concreta, el profesor oficial representante de las demás asignaturas y una "persona extraña" que actúa como Secretario del tribunal.

En las actas del curso académico 1914-1915 se encuentra el primer "expediente de oposición verificada en esta escuela para la provisión de la beca concedida en este 
centro por R.O. de 26 de abril de 1915”. En 4 de junio de 1915 se empiezan a insertar las calificaciones estampadas en tinta. De igual modo en el curso 1916-1917 se celebran por primera vez los exámenes para obtener las matrículas de honor. En las actas del curso académico 1919-1920 se reúne el tribunal que habrá de juzgar la aptitud pedagógica de una maestra nacional "rehabilitada por R.O de 4 de agosto del corriente año”.

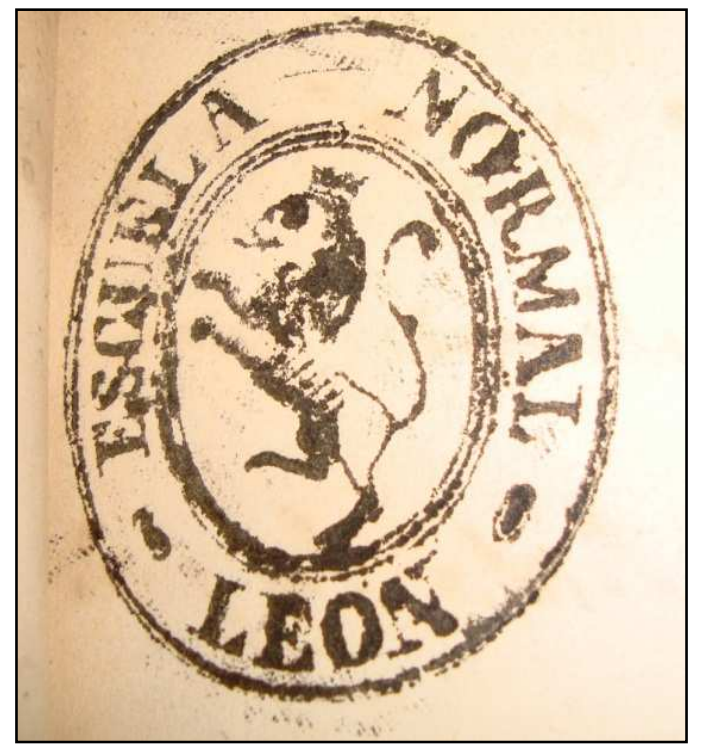

Ilustración 3. Primer sello de la Escuela Normal de León, corresponde al libro 1 de actas de exámenes. Fotografía de Carmen Rodríguez López

\section{Conclusión}

La visión educativa del archivo abre nuevas oportunidades. No sólo el tradicional Archivo Histórico es susceptible de visita. Otros centros pueden poner sus recursos al servicio de la institución productora y de la sociedad que la produce, a la que refleja indefectiblemente. Sin duda es necesaria la tarea previa de organización y descripción del fondo para lanzarlo al mundo del aprendizaje, pero la adquisición de determinadas competencias podría verse beneficiada por el uso de los fondos de cada institución.

\section{Notas}

1. http://www3.unileon.es/ce/fce/?q=content/historia-de-la-facultad.

2. Debemos agradecer un buen aporte de estos datos a Javier Díaz Barrera, administrativo del Centro, y a Pablo Celada Perandones, quien investigó antes que nosotros sobre este fondo.

3. https://unixxi.unileon.es/uxxiinve/publico/ListarConsultaGruposInv.do? modulo $=$ cur\&pantalla $=$ ConsultaGruposInv\&numPagina $=1$

4. 16/1985 del Patrimonio Histórico Español, B.O.E. núm. 155, de 29 de junio de 1985. art. 57 c): Los documentos que contengan datos personales de carácter policial, procesal, clínico o cualquier otra índole que puedan afectar a la seguridad de la persona, a su honor, a la intimidad de su vida privada y familiar, y a su persona e imagen no podrán ser públicamente consultados sin que medie consentimiento expreso de los afectados o hasta que haya transcurrido un plazo de veinticinco años desde su muerte, si su fecha es conocida. En el caso de no serlo, cincuenta 
años a partir de la fecha de los documentos.

5. No es posible sugerir cuántos estudios se podrían llevar a cabo sobre este fondo, pero en este punto podemos mencionar los sellos de ayuntamientos y parroquias.

\section{Bibliografía}

Alas y Urueña, L. (pseud. Clarín), (1861), En los exámenes públicos de la Escuela Práctica agregada a la Normal Superior de León, celebrados en los días 23 y 24 de junio de $1861 \ldots$, Viuda e hijos de Miñón, León.

Álvarez Oblanca, W. (1986), La represión de posguerra en León: Depuración de la Enseñanza 19361943, Santiago García, León.

Celada Perandones, P. (1992), "Análisis y cuantificación del Magisterio Primario en León durante la segunda mitad del s. XIX", Estudios Humanísticos. Geografía, Historia, Arte, (León), Nº 14, pp.51-65.

Celada Perandones, P. (1996), "La Escuela Normal de León: un paseo por los planes de estudio en busca de los contenidos pedagógicos, didácticos e históricos-educativos”, en Marín, T., Navarro, C. y Aragón, M., Formación de profesores y Educación Social. Actas de las III Jornadas de Teorías e Instituciones Educativas Contemporáneas. Universidad de Catilla-La Mancha, Cuenca, pp. 243-270.

Celada Perandones, P. (2004), "De Escuela Normal a Facultad de Educación”, en Paniagua Pérez, J. (coord.), Hacia la Universidad de León: estudios de historia de la educación en León, Universidad, León, pp. 405-438.

Cordero del Campillo, M. (1983), La Universidad de León: de la Escuela de Veterinaria la Universidad, Everest, León.

España. Constitución Española de 1978. Boletín Oficial del Estado, 29 de diciembre 1978, № 311.1

España. "Real Decreto de 31 de agosto de 1834", Gaceta de Madrid, 3 de septiembre, 1834.

España. "Real Decreto de 4 de octubre de 1843”, Gaceta de Madrid, 7 de octubre, 1843.

España. "Ley 1/1982 de 5 de mayo de Protección civil del Derecho al Honor, a la Intimidad Personal y Familiar y a la Propia Imagen”, Boletín Oficial del Estado, 14 de mayo 1982, № 115.

España. “Ley 16/1985, de 25 de junio, del Patrimonio Histórico Español”, Boletín Oficial del Estado, 29 de junio $1985, \mathrm{~N}^{\circ} 155$.

España. "Ley Orgánica 5/1992 de 29 de octubre de Regulación del Tratamiento Automatizado de los datos de Carácter Personal”, Boletín Oficial del Estado, 31 de octubre 1992, Nº 262.

España. "Ley 30/1992, de 26 de noviembre, de Régimen Jurídico de las Administraciones Públicas y del Procedimiento Administrativo Común”, Boletín Oficial del Estado, 27 de noviembre 1992.

España. "Ley 4/1999, de modificación de la Ley 30/1992, de 26 de noviembre, de Régimen Jurídico de las Administraciones Públicas y del Procedimiento Administrativo Común”, Boletín Oficial del Estado, 14 de enero $1999, \mathrm{~N}^{\circ} 12$.

España. "Ley Orgánica 15/1999, de 13 de diciembre de Protección de Datos de Carácter Personal”, Boletín Oficial del Estado, 14 de diciembre 1999, Nº. 298.

España. "Orden de 13 de junio de 1977 sobre directrices para la elaboración de los planes de estudio de las Escuelas Universitarias del Profesorado de Educación General Básica”, Boletín Oficial del Estado, 25 de junio 1977, $\mathrm{N}^{\circ} 151$, pp. 14256-14257. 
MEI, II, Vol. 3, nº 4, pág. 59

Flecha Andrés, F. (coord.), (1995), La escuela que vivimos: publicación con motivo de la celebración del 150 aniversario de la fundación de la Escuela Normal de Maestros (1844-1994), Universidad, Secretariado de Publicaciones, León.

Martínez Pereda, L. (2008), La depuración del magisterio en la comarca de Benavente. Zamora. Instituto Ledo del Pozo, Benavente.

Ramos, R. (1988), "Memoria”, en Salvador Giner et al. (eds.), Diccionario de Sociología, Alianza, Madrid.

Real Academia Española, (2001), Diccionario de la lengua española, 22. ${ }^{a}$ ed., Espasa, Madrid.

Rodríguez González, J. (2003), León bajo la dictadura franquista (1936-1951). Universidad, León. 